\title{
Canagliflozin Increases Postprandial Total Glucagon-Like Peptide 1 Levels in the Absence of $\alpha$-Glucosidase Inhibitor Therapy in Patients with Type 2 Diabetes: A Single-Arm, Non-randomized, Open-Label Study
}

\author{
Takeshi Osonoi · Atsuko Tamasawa · Yusuke Osonoi • \\ Kensuke Ofuchi · Makoto Katoh (D) - Miyoko Saito
}

Received: July 18, 2019 / Published online: September 10, 2019

(C) The Author(s) 2019

\begin{abstract}
Introduction: To investigate canagliflozin-induced changes in postprandial total glucagonlike peptide 1 (GLP-1) and glucose-dependent insulinotropic polypeptide (GIP) levels in patients with type 2 diabetes mellitus (T2DM).

Methods: Forty-five patients with T2DM who had inadequate glycemic control (glycated hemoglobin $\geq 6.5 \%$ ) with diet and exercise alone ( $n=15$, drug naïve) and in combination with either a stable dose of the $\alpha$-glucosidase inhibitor acarbose $(n=15)$ or metformin $(n=15)$ received canagliflozin, a sodium-glucose cotransporter 2 inhibitor, at $100 \mathrm{mg}$ once daily for 12 weeks. The primary endpoint was the change from baseline to week 12 in postprandial glucose and plasma levels of total GLP1 and GIP during a meal tolerance test (MTT).
\end{abstract}

Enhanced Digital Features To view enhanced digital features for this article go to https://doi.org/10.6084/ m9.figshare.9741326.

Electronic supplementary material The online version of this article (https://doi.org/10.1007/s13300019-00689-w) contains supplementary material, which is available to authorized users.

T. Osonoi · A. Tamasawa · Y. Osonoi · K. Ofuchi · M. Katoh $(\varangle) \cdot$ M. Saito

Naka Kinen Clinic, 745-5 Nakadai, Naka,

Ibaraki 311-0113, Japan

e-mail: m-katou@kensei-kai.com
Results: Canagliflozin significantly reduced postprandial blood glucose (mean difference - $40.2 \mathrm{mg} / \mathrm{mL}$ at $60 \mathrm{~min}$ ) and increased postprandial total GLP-1 (mean difference $1.8 \mathrm{pg} /$ $\mathrm{mL}$ at $60 \mathrm{~min}$ ) during an MTT. A transient reduction in the postprandial GIP level at only $30 \mathrm{~min}$ (mean difference $-80.3 \mathrm{pg} / \mathrm{mL}$ ) during an MTT was observed. No changes in postprandial GLP-1 or GIP levels were seen after canagliflozin treatment as an add-on to acarbose in patients with T2DM. Acarbose treatment significantly decreased postprandial total GIP levels $(P<0.05)$ and tended to increase postprandial total GLP-1 levels $(P=0.07)$ compared to the other two treatments prior to canagliflozin.

Conclusion: Canagliflozin $100 \mathrm{mg}$ increased postprandial total GLP-1 levels in the absence of acarbose, suggesting that it may upregulate GLP-1 secretion through delayed glucose absorption in the upper intestine, as with the $\alpha$ glucosidase inhibitor.

Trial Registration: University Hospital Medical Information Network, UMIN000018345.

Funding: Mitsubishi Tanabe Pharma Corporation.

Keywords: Canagliflozin; GLP-1; SGLT1; SGLT2 inhibitor; Type 2 diabetes 


\section{INTRODUCTION}

Sodium-glucose cotransporter 2 (SGLT2) inhibitors are a new class of diabetic medications that inhibit renal glucose reabsorption, promote glucosuria, and effectively reduce glycated hemoglobin (HbA1c), providing hypoglycemiafree glucose control in patients with type 2 diabetes mellitus (T2DM) [1, 2]. Currently, of the six SGLT2 inhibitors commercially available in Japan, canagliflozin has a lower SGLT2 selectivity of 155-fold over SGLT1 and 250-3000-fold selectivity compared with other SGLT2 inhibitors [3].

SGLT1 is highly expressed on the brushborder membrane of enterocytes in the proximal intestine and plays a role in glucose absorption [4, 5]. Thus, the intestinal SGLT1 inhibition lowers serum glucose levels and conversely augments distal intestinal glucose levels. Incretins, such as glucose-dependent insulinotropic polypeptide (GIP) from K cells and glucagon-like peptide 1 (GLP-1) from L cells in the intestine, are hormones that are released from the gut into the bloodstream in response to nutrient ingestion [6-8]. SGLT1 is also expressed in the proximal tubule, heart, skeletal muscle, and others $[9,10]$. Experiments suggest that canagliflozin exhibited modest potency against SGLT1 in the intestine as a result of delayed glucose absorption and increased GLP-1 secretion [11], as well as SGLT2 inhibition in the proximal tubule. In clinical studies with healthy subjects [12, 13], a single dose of orally administered canagliflozin $300 \mathrm{mg}$ transiently delayed intestinal glucose absorption, probably as a result of SGLT1 inhibition, which resulted in a reduction in plasma GIP levels and an increase in plasma GLP-1 levels [12].

The $\alpha$-glucosidase inhibitors ( $\alpha$-GIs) inhibit $\alpha$ glucosidase enzymes in the intestinal brush borders, leading to a delay in the digestion of complex carbohydrates and absorption of glucose in the upper part of the small intestine. This process is mediated by lower GIP levels and improves postprandial hyperglycemia [14-16]. Furthermore, a delay in glucose absorption by $\alpha$-GIs accelerates GLP-1 secretion in the lower intestine and, consequently, increases plasma GLP-1 levels, which partly contributes to the inhibition of postprandial hyperglycemia $[15,16]$.

Metformin has also been reported to increase plasma GLP-1 levels after a test meal in patients with T2DM [17-19]. The mechanisms underlying the increased plasma GLP-1 levels associated with metformin treatment are poorly understood. Metformin has been suggested to inhibit the apical sodium-dependent bile acid transporter in the ileum, thereby increasing the luminal concentration of bile acids in the ileum and colon [18]. Exogenous bile acids increase circulating GLP-1 in clinical studies $[20,21]$. Thus, metformin induces GLP-1 secretion indirectly through an increase in bile acids in the intestine.

The present study aimed to investigate the effects of canagliflozin $100 \mathrm{mg}$ once daily for 12 weeks on blood glucose control and postprandial total GLP-1 levels in Japanese patients with T2DM, as either single or combination therapy with $\alpha$-GI or metformin, both of which are known to potentiate GLP-1 secretion.

\section{METHODS}

\section{Study Subjects}

This was a 12-week, open-label study conducted at Naka Kinen Clinic (Ibaraki, Japan). The study protocol was approved by the Naka Kinen Clinic Institutional Review Board, Ibaraki, Japan, and is registered in the University Hospital Medical Information Network Clinical Trials Registry as UMIN000018345. All procedures performed in this study involving human participants were in accordance with the ethical standards of the responsible committee on human experimentation (institutional and national) and the Helsinki Declaration of 1964, as revised in 2013. Informed consent was obtained from all individual participants included in the study. Participants were compensated for their time.

Eligible participants were patients aged at least 20 years and less than 75 years with T2DM who met the following criteria: (1) had a baseline $\mathrm{HbA} 1 \mathrm{c}$ between $6.5 \%$ and $8.5 \%$, and (2) underwent regular dietary or exercise therapy for at least 8 weeks, or took stable doses of oral glucose-lowering agents of $\alpha$-GI or metformin 
for at least 8 weeks. Patients who met at least one of the following criteria were excluded from the study: (1) had type 1 diabetes mellitus or secondary diabetes mellitus; (2) had a contraindication to canagliflozin; (3) had severe renal dysfunction (estimated glomerular filtration rate less than $30 \mathrm{~mL} / \mathrm{min} / 1.73 \mathrm{~m}^{2}$ ); (4) had a body mass index (BMI) less than $22 \mathrm{~kg} / \mathrm{m}^{2}$; (5) were receiving glucose-lowering therapy by insulin, GLP-1 analogues, or other SGLT2 inhibitors; (6) were pregnant, breast-feeding or planning to be pregnant; or (7) were deemed by the investigator to be not suitable, e.g., patients with a complication or history of cerebral or myocardial infarction.

\section{Study Design}

Patients with T2DM inadequately controlled by a regular diet and exercise therapy regimen (classified as the drug-naïve group), acarbose (the $\alpha$-GI group), or metformin (the metformin group) for at least 8 weeks were enrolled and given canagliflozin $100 \mathrm{mg}$ once daily for 12 weeks. The meal tolerance tests (MTTs) were carried out before and after canagliflozin treatment for 12 weeks. A meal was about $504 \mathrm{kcal}$ and consisted of $63.1 \%$ carbohydrate, $12.4 \%$ protein, and $23.2 \%$ fat. For the MTTs, canagliflozin $100 \mathrm{mg}$ was administered $30 \mathrm{~min}$ before the start of the meal and blood samples were collected at four time points: before a meal and 30, 60, and $90 \mathrm{~min}$ after a meal to measure blood glucose, total GIP, total GLP-1, and immunoreactive insulin levels.

To assess glycemic control and anthropometric variables, HbA1c, glycoalbumin, body weight, and BMI were measured before and every 4 weeks during the canagliflozin treatment period of 12 weeks. The waist circumference was also measured before and after a 12 -week treatment with canagliflozin.

\section{Measurement of Total GIP and GLP-1 \\ Levels, Immunoreactive Insulin, Homeostatic Model Assessment (HOMA)-R, and HOMA-Beta Cell Function (HOMA-B)}

Plasma total GIP levels were measured with an ELISA kit that had $100 \%$ cross-reactivity to human active GIP and inactive GIP (EMD Millipore Corporation, MO, USA) $[22,23]$. The detection limit of total GIP in this assay was $0.8 \mathrm{pmol} / \mathrm{L}$. Plasma total GLP-1 levels were determined by an electrochemiluminescent immunoassay kit (Meso Scale Diagnostic LLC, MD, USA) [23]. The detection limit of total GLP-1 in this assay was $0.4 \mathrm{pmol} / \mathrm{L}$. Values below the detection limit were calculated as half values of the detection limit. Serum immunoreactive insulin levels were measured with a chemiluminescent enzyme immunoassay kit from SRL Inc (Tokyo, Japan). Two samples were missing in both the drug-naïve group and the metformin group. HOMA-R, an index of insulin resistance, and HOMA-B were calculated as follows [24]; HOMA-R $=$ insulin $\times$ fasting blood glucose $/ 405$, HOMA-B $=$ insulin $\times 360 /(-$ fasting blood glucose -63 ).

\section{Statistical Analysis}

Data in all tables and figures are presented as the arithmetic mean \pm standard deviation (SD) unless otherwise stated. An incremental area under the curve $(\triangle \mathrm{AUC}$; defined as AUC above the value before a meal in an MTT) from 0 to 90 min was calculated using the trapezoidal rule for blood glucose, total GIP, and total GLP-1 levels during MTTs. For HbA1c, glycoalbumin, body weight, BMI, waist circumference, HOMA$\mathrm{R}$, and HOMA-B, statistical differences between pre- and post-treatment at each time point $(4,8$, 12 weeks) were analyzed using paired $t$ tests. The same method was used to detect the statistical significance for blood glucose, total GIP and GLP1 , and immunoreactive insulin levels during an MTT between pre- and post-treatment at each time point (before a meal, 30, 60, and $90 \mathrm{~min}$ after a meal). $\triangle$ AUCs were analyzed using paired $t$ tests to detect the difference between pre- and post-treatment. Analyses were performed in all patients by group. In addition, a one-way analysis of variance was used to compare baseline values of $\triangle \mathrm{AUCs}$, the percentage change of $\triangle$ AUCs from baseline, and continuous data on patients' demographics/baseline characteristics between groups, followed by the Bonferroni post hoc test. $P<0.05$ at a two-sided level was considered statistically significant. Pearson's 
correlation coefficient tests were applied to assess the correlation between numerical variables. Statistical analyses were performed using SAS ver. 9.2 (SAS Institute Japan Ltd., Tokyo, Japan).

\section{RESULTS}

\section{Patient Disposition and $\triangle A U C s$ at Baseline}

Forty-eight patients with T2DM, who were eligible for the study and provided informed consent, were enrolled. Three patients were excluded from the study because of withdrawal of informed consent. The remaining 45 patients were enrolled and received canagliflozin $100 \mathrm{mg}$. Each group (drug naïve, $\alpha-\mathrm{GI}$, and metformin) consisted of 15 patients. All 45 participants completed the study over 12 weeks and underwent examinations specified in the study protocol. Dose levels of $\alpha$-GI (acarbose) and metformin were 150-300 and 500-$2250 \mathrm{mg} /$ day, respectively.

Patient demographics and baseline characteristics by group were similar between groups except for the sex ratio, age, fasting blood glucose, and HOMA-R (Table 1). The mean fasting blood glucose and HOMA-R were significantly higher in the $\alpha$-GI group than that in the metformin group $(P<0.01)$ and the drug-naïve group $(P<0.05)$, respectively before treatment with canagliflozin (Table 1 ), but there were no statistically significant difference among the groups after treatment with canagliflozin for 12 weeks. Significantly lower baseline $\triangle A U C$ values for postprandial glucose $(P<0.01$; Fig. 1e) and total GIP levels $(P<0.05$; Fig. 3e) were noted in the $\alpha$-GI group than in the other groups. $\triangle$ AUC of the total GLP-1 level was higher in the $\alpha$-GI group than in the other groups, although it did not reach statistical significance $(P=0.07$; Fig. $2 \mathrm{e})$.

\section{Blood Parameters After an MTT}

The time courses of blood glucose (Fig. 1a-d), total GLP-1 (Fig. 2a-d), total GIP (Fig. 3a-d), and immunoreaction insulin (Fig. 4a-d) levels, together with their $\triangle \mathrm{AUCs}$, during the MTTs before and after treatment with canagliflozin for 12 weeks for all patients and by group showed significant changes in all parameters analyzed.

Blood glucose levels were significantly reduced at all time points (mean difference \pm SD $\quad-17.7 \pm 21.6, \quad-35.8 \pm 28.5$, $-40.2 \pm 28.7$, and $-37.4 \pm 32.7 \mathrm{mg} / \mathrm{dL}$ at 0 , 30,60 , and $90 \mathrm{~min}$ after a meal, respectively), regardless of the group $(P<0.01)$, and, as a result, $\triangle$ AUCs significantly decreased $(P<0.01)$. Despite lower baseline postprandial hyperglycemia in the $\alpha$-GI group than in the other groups before treatment with canagliflozin, a lowering effect on postprandial glucose levels was observed in this group, which was similar in extent to that in the metformin group after treatment with canagliflozin for 12 weeks. The percentage change in $\triangle \mathrm{AUC}$ of blood glucose levels from baseline in the $\alpha$-GI group was small, but not significantly between the two groups (Fig. 1f).

Postprandial plasma total GLP-1 levels after treatment with canagliflozin were significantly increased at all time points $(P<0.05$ or $P<0.01$ ) in all patients (mean difference \pm SD $0.1 \pm 1.8, \quad 1.1 \pm 3.3, \quad 1.8 \pm 3.1, \quad$ and $1.1 \pm 3.2 \mathrm{pmol} / \mathrm{L}$ at $0,30,60$, and $90 \mathrm{~min}$ after a meal, respectively) and in the metformin group (mean difference $\pm \mathrm{SD}-0.6 \pm 1.7,2.7 \pm 4.0$, $2.3 \pm 2.7$, and $1.8 \pm 3.1 \mathrm{pmol} / \mathrm{L}$ at $0,30,60$, and $90 \mathrm{~min}$ after a meal, respectively), and at $60 \mathrm{~min}$ in the drug-naïve group (mean difference $\pm S D-0.5 \pm 0.5, \quad 0.9 \pm 2.5,2.0 \pm 2.3$, and $1.4 \pm 2.6 \mathrm{pmol} / \mathrm{L}$ at $0,30,60$, and $90 \mathrm{~min}$ after a meal, respectively) during the MTT $(P<0.01)$, which led to a significant increase in $\triangle$ AUCs $(P<0.01)$.

In contrast, the postprandial total GIP level was significantly reduced at only $30 \mathrm{~min}$ in all patients (mean difference \pm SD $2.4 \pm 9.9$, $-16.1 \pm 19.0,-7.60 \pm 28.0$, and $2.36 \pm 27.9$ $\mathrm{pmol} / \mathrm{L}$ at $0,30,60$, and $90 \mathrm{~min}$ after a meal, respectively), the drug-naïve group (mean difference \pm SD $0.2 \pm 8.7,-24.0 \pm 15.9,-12.3$ \pm 27.8 , and $-5.5 \pm 21.2 \mathrm{pmol} / \mathrm{L}$ at $0,30,60$, and 90 min after a meal, respectively), and the metformin group (mean difference \pm SD $3.1 \pm$ $11.1,-17.5 \pm 21.2,-7.8 \pm 33.7$, and $5.1 \pm$ $32.5 \mathrm{pmol} / \mathrm{L}$ at $0,30,60$, and $90 \mathrm{~min}$ after a meal, respectively) during the MTT $(P<0.01)$. 
Table 1 Baseline characteristics

\begin{tabular}{|c|c|c|c|c|c|}
\hline & $\begin{array}{l}\text { All subjects } \\
\left(n=45 \text { or } 41^{\mathrm{e}}\right)\end{array}$ & $\begin{array}{l}\text { Drug-naïve } \\
\text { group } \\
\left(n=15 \text { or } 13^{\mathrm{e}}\right)\end{array}$ & $\begin{array}{l}\alpha-G I \text { group } \\
(n=15)\end{array}$ & $\begin{array}{l}\text { Metformin } \\
\text { group } \\
\left(n=15 \text { or } 13^{\mathrm{e}}\right)\end{array}$ & $\begin{array}{l}\text { 3-Group } \\
\text { comparisons }\end{array}$ \\
\hline Male, $n(\%)$ & $30(66.7 \%)$ & $13(86.7 \%)$ & $11(73.3 \%)$ & $6(40.0 \%)$ & $P=0.04^{\mathrm{a}}$ \\
\hline Age, years & $54.0 \pm 10.9$ & $55.1 \pm 10.0$ & $48.3 \pm 11.5$ & $58.5 \pm 9.1$ & $P=0.03^{\mathrm{b}}$ \\
\hline $\mathrm{HbAlc}, \%(\mathrm{mmol} / \mathrm{mol})$ & $\begin{array}{l}7.1 \pm 0.6 \\
\quad(53.8 \pm 7.0)\end{array}$ & $\begin{array}{l}7.3 \pm 0.7 \\
\quad(55.4 \pm 7.8)\end{array}$ & $\begin{array}{l}7.2 \pm 0.8 \\
\quad(54.7 \pm 8.5)\end{array}$ & $\begin{array}{l}6.9 \pm 0.3 \\
\quad(51.3 \pm 3.2)\end{array}$ & $P=0.19$ \\
\hline Glycoalbumin, \% & $17.5 \pm 2.3$ & $18.3 \pm 2.0$ & $17.8 \pm 2.5$ & $16.5 \pm 2.0$ & $P=0.08$ \\
\hline $\begin{array}{l}\text { Fasting blood glucose, } \\
\mathrm{mg} / \mathrm{dL}\end{array}$ & $140.0 \pm 23.8$ & $139.9 \pm 20.3$ & $152.8 \pm 28.4$ & $127.4 \pm 14.4$ & $P=0.01^{\mathrm{c}}$ \\
\hline Body weight, $\mathrm{kg}$ & $76.4 \pm 15.9$ & $75.3 \pm 9.7$ & $81.4 \pm 19.6$ & $72.4 \pm 16.3$ & $P=0.29$ \\
\hline Body mass index, $\mathrm{kg} / \mathrm{cm}^{2}$ & $28.3 \pm 4.2$ & $27.3 \pm 3.4$ & $29.2 \pm 5.5$ & $28.3 \pm 3.4$ & $P=0.48$ \\
\hline Waist circumference, $\mathrm{cm}$ & $96.9 \pm 10.6$ & $93.9 \pm 7.0$ & $100.6 \pm 13.2$ & $96.1 \pm 10.2$ & $P=0.22$ \\
\hline HOMA-R & $3.6 \pm 2.2$ & $2.8 \pm 1.0$ & $4.9 \pm 3.0$ & $3.0 \pm 1.5$ & $P=0.03^{\mathrm{d}}$ \\
\hline HOMA-B & $49.3 \pm 24.1$ & $41.2 \pm 14.4$ & $52.0 \pm 24.8$ & $54.3 \pm 30.1$ & $P=0.43$ \\
\hline $\begin{array}{c}\text { Duration of type } 2 \\
\text { diabetes, years }\end{array}$ & $5.2 \pm 3.7$ & $3.8 \pm 3.5$ & $5.6 \pm 3.7$ & $6.2 \pm 3.8$ & $P=0.18$ \\
\hline \multicolumn{6}{|l|}{ Complication, $n(\%)$} \\
\hline Retinopathy & $11(24.4 \%)$ & $4(26.7 \%)$ & $4(26.7 \%)$ & $3(20.0 \%)$ & $P=0.89$ \\
\hline Nephropathy & $10(22.2 \%)$ & $5(33.3 \%)$ & $2(13.3 \%)$ & $3(20.0 \%)$ & $P=0.55$ \\
\hline Nerve disorders & $8(17.8 \%)$ & $2(13.3 \%)$ & $3(20.0 \%)$ & $3(20.0 \%)$ & $P=1.00$ \\
\hline
\end{tabular}

Data are presented as the mean $\pm S D$

$G I$ glucosidase inhibitor, $S D$ standard deviation

a $P<0.05$ for the comparison of male sex (\% of total) between the drug-naïve group and the metformin group

b $P<0.05$ for the comparison of age between the $\alpha$-GI group and the metformin group

c $P<0.05$ for the comparison of fasting blood glucose between the $\alpha$-GI group and the metformin group

d $P<0.05$ for the comparison of HOMA-R between the drug-naive group and the $\alpha$-GI group

e Two samples (HOMA-R and HOMA-B) were missing in both the drug-naïve group and the metformin group

$\triangle$ AUC significantly decreased in all patients and the drug-naïve group $(P<0.05)$, but not in the metformin group.

In the $\alpha$-GI group, no changes in postprandial total GLP-1 (mean difference \pm SD $0.9 \pm 2.4,-0.3 \pm 2.6,1.0 \pm 4.0$, and $0.3 \pm 3.9$ $\mathrm{pmol} / \mathrm{L}$ at $0,30,60$, and $90 \mathrm{~min}$ after a meal, respectively) or GIP levels (mean difference \pm SD $4.0 \pm 10.1, \quad-6.8 \pm 16.6,-2.8 \pm$ 22.7, and $7.5 \pm 29.0 \mathrm{pmol} / \mathrm{L}$ at $0,30,60$, and 90 min after a meal, respectively) were seen during the MTT after treatment with canagliflozin. The percentage changes in $\triangle \mathrm{AUC}$ of total GLP-1 and GIP levels from baseline in the $\alpha$-GI group were both slight, but the latter was not significantly different between the groups (Figs. 2f, 3f, respectively).

Immunoreactive insulin levels after treatment with canagliflozin were significantly reduced at all time points in all patients (mean difference \pm SD $\quad-1.5 \pm 2.8, \quad-5.7 \pm 6.9$, $-7.1 \pm 8.8$, and $-6.9 \pm 11.5 \mathrm{mg} / \mathrm{dL}$ at 0,30 , 60 , and 90 min after a meal, respectively), at 30, 60 , and $90 \mathrm{~min}$ in the drug-naïve group, at 30 
(a)

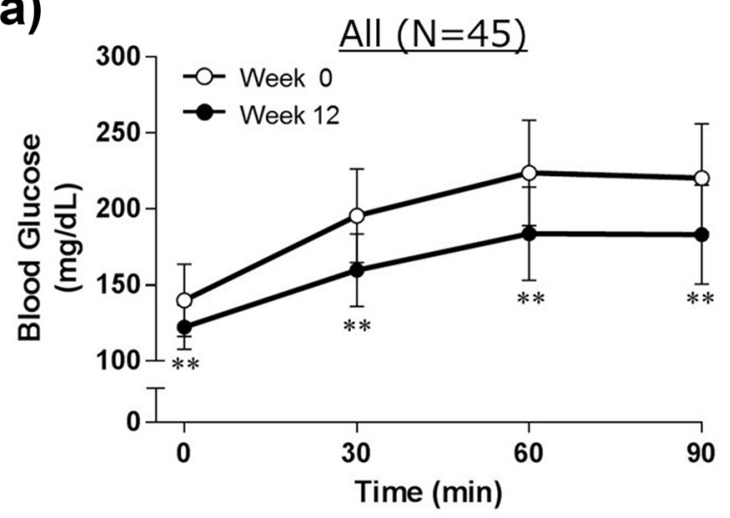

(c)

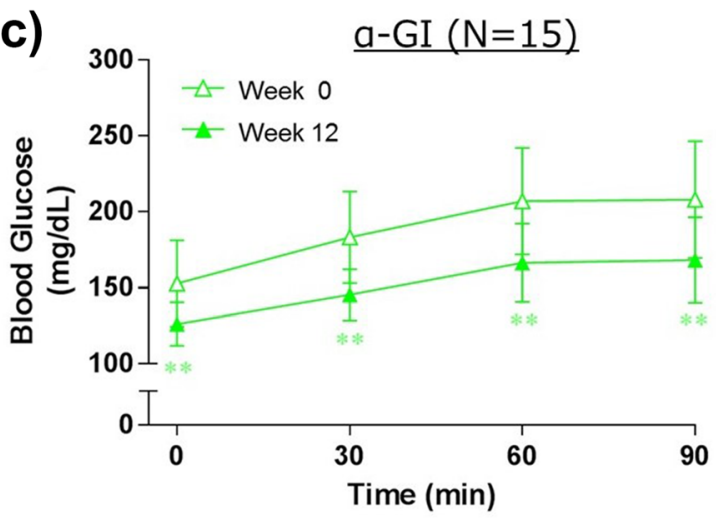

(e)

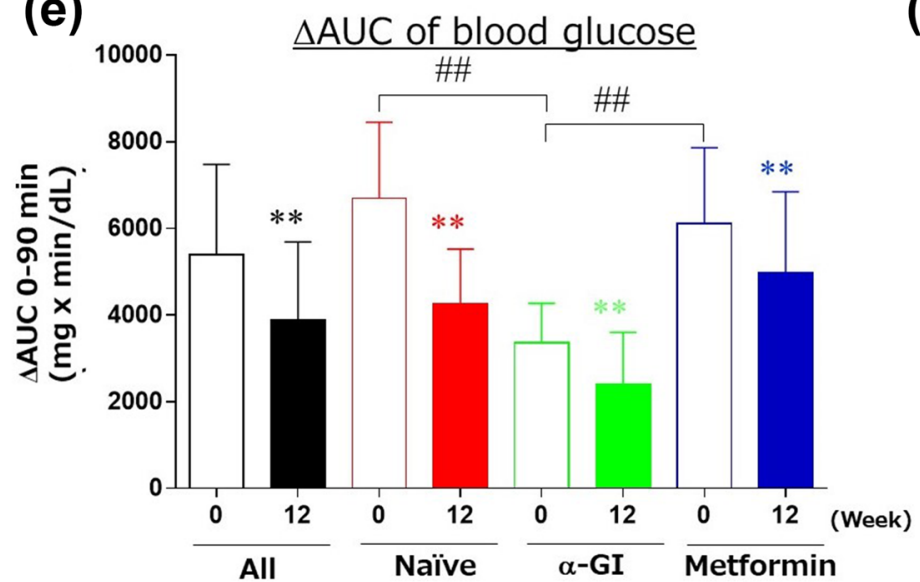

(b)
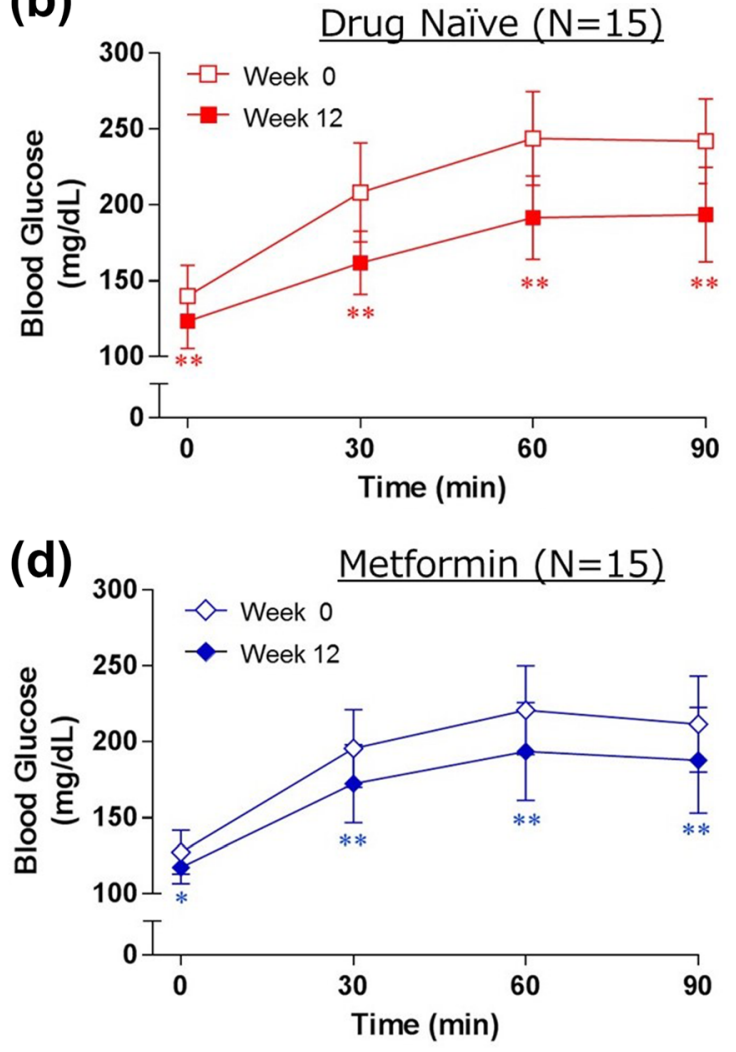

(f)

$\%$ change in $\triangle \mathrm{AUC}$ of blood glucose

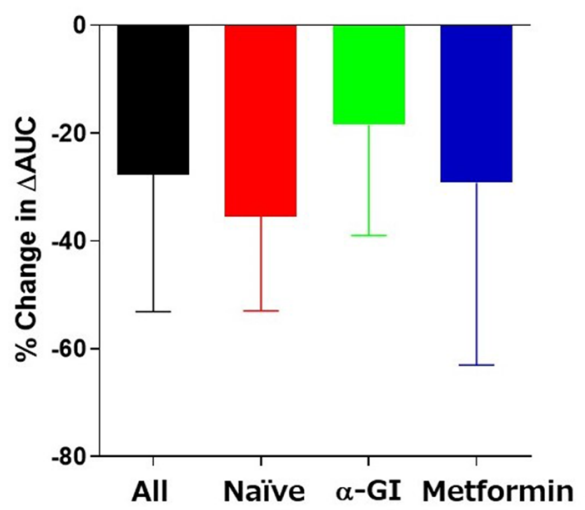

Fig. 1 Effect of canagliflozin on postprandial blood glucose in all patients $(\mathbf{a})$, the drug-naive group $(\mathbf{b})$, the $\alpha$-GI group (c), and the metformin group (d), and on an incremental area under the curve $(\triangle \mathrm{AUC})$ from 0 to $90 \mathrm{~min}(\mathbf{e})$, and the percentage change in $\triangle \mathrm{AUC}(\mathbf{f})$. Data are presented as the mean $\pm S D .{ }^{*} P<0.05$ and ${ }^{* *} P<0.01$ in comparison with baseline (week 0 ) at each time point and that between pre- and post-treatment of canagliflozin in $\triangle$ AUC. ${ }^{\# \#} P<0.01$ for the comparison of $\triangle$ AUC at baseline between the $\alpha$-GI group and the other two groups. No statistical differences were noted between the three groups in the percentage change in $\triangle \mathrm{AUC}$. GI glucosidase inhibitor, SD standard deviation 
(a)

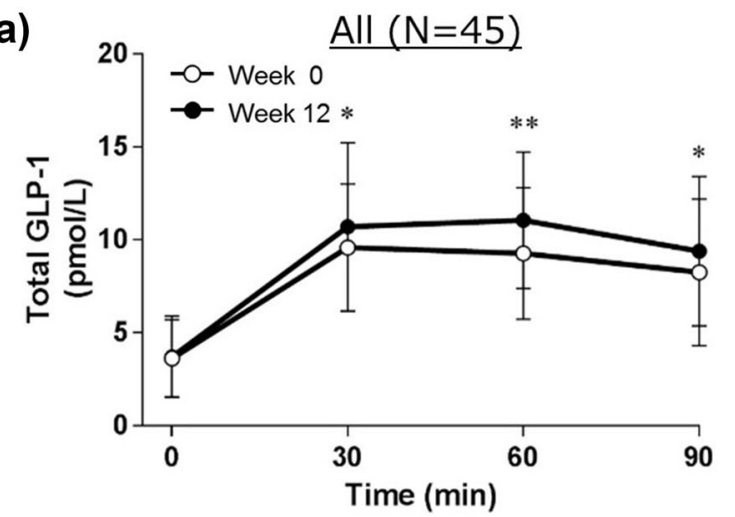

(c)

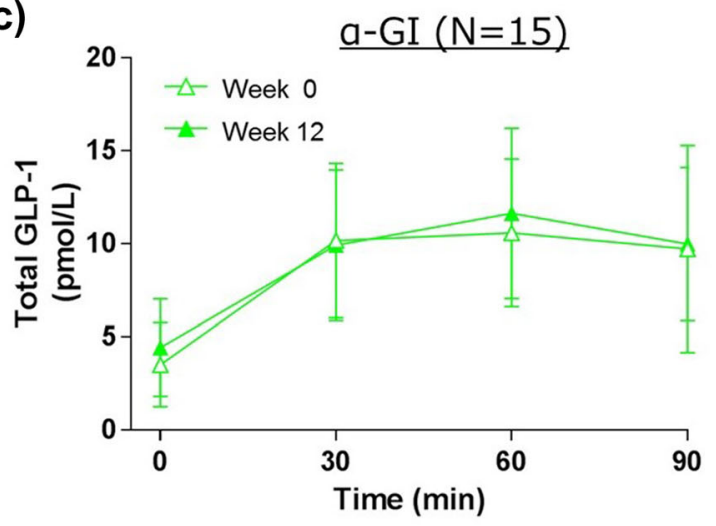

(e)

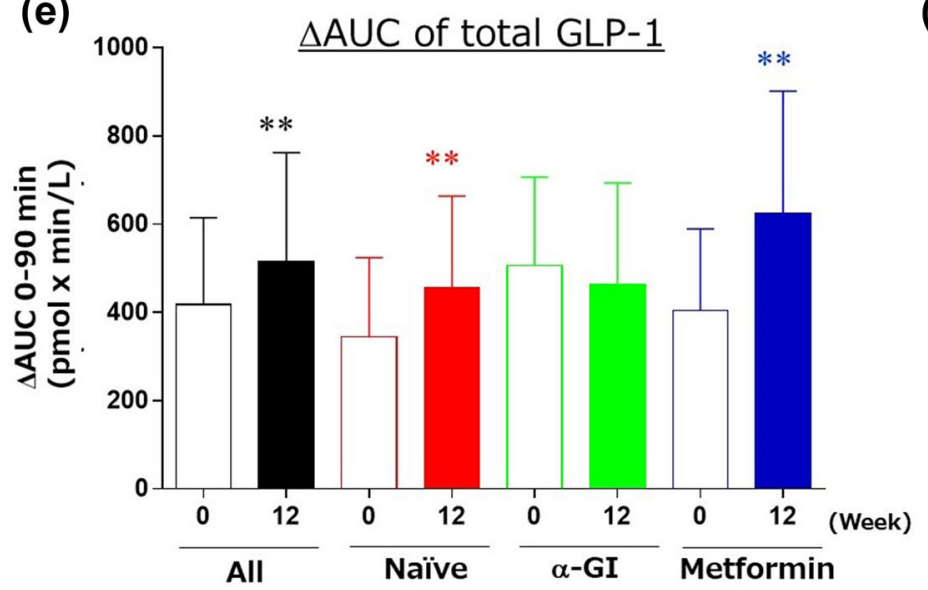

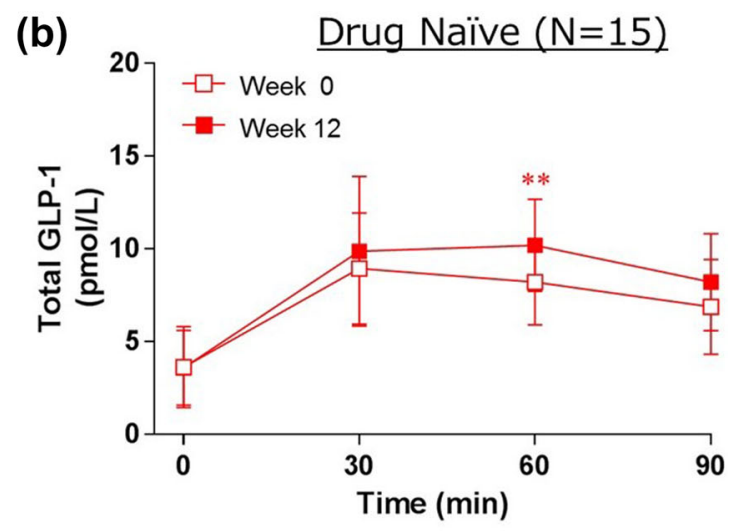

(d)

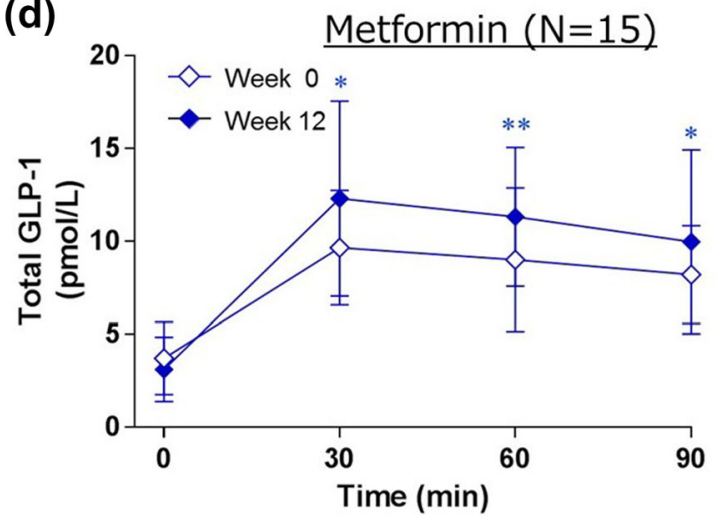

(f)

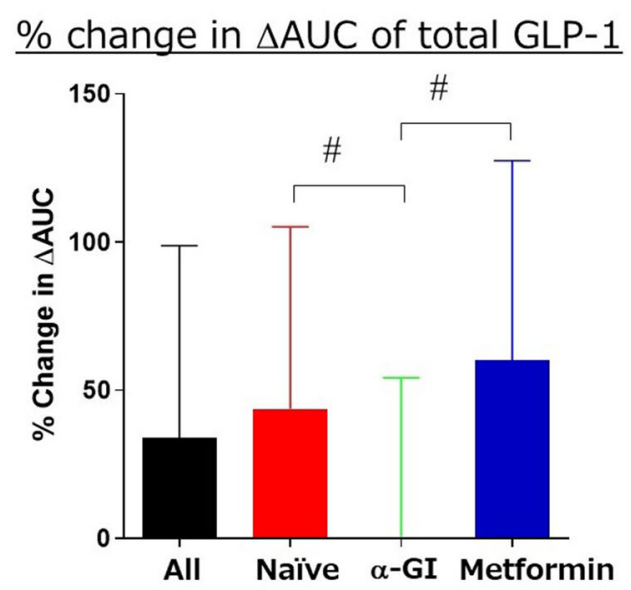

Fig. 2 Effect of canagliflozin on the postprandial plasma total GLP-1 level in all patients (a), the drug-naïve group (b), the $\alpha$-GI group (c), and the metformin group (d), and on an incremental area under the curve $(\triangle \mathrm{AUC})$ from 0 to $90 \mathrm{~min}(\mathbf{e})$, and the percentage change in $\triangle \mathrm{AUC}(\mathbf{f})$. Data are presented as the mean $\pm \mathrm{SD} .{ }^{*} P<0.05$ and ${ }^{* *} P<0.01$ in comparison with baseline (week 0 ) at each time point and that between pre- and post-treatment of canagliflozin in $\triangle \mathrm{AUC}$. No statistical differences were noted between the 3 groups in $\triangle \mathrm{AUC}$ at baseline $(P=0.07) .{ }^{\#} P<0.05$ for the comparison of the percentage change in $\triangle \mathrm{AUC}$ between the $\alpha$-GI group and the other two groups. GLP-1 glucagon-like peptide 1, GI glucosidase inhibitor, SD standard deviation 
(a)

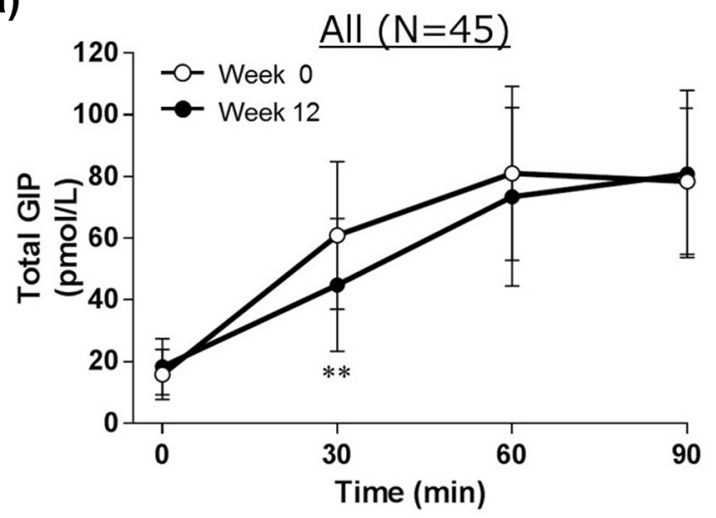

(c)

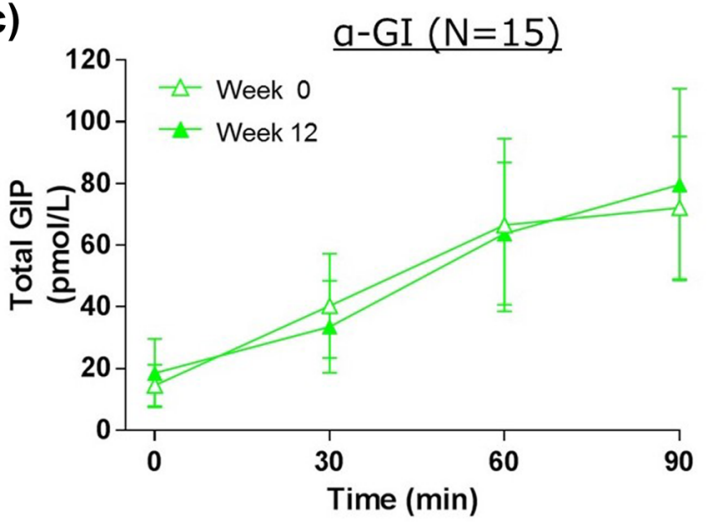

(e)

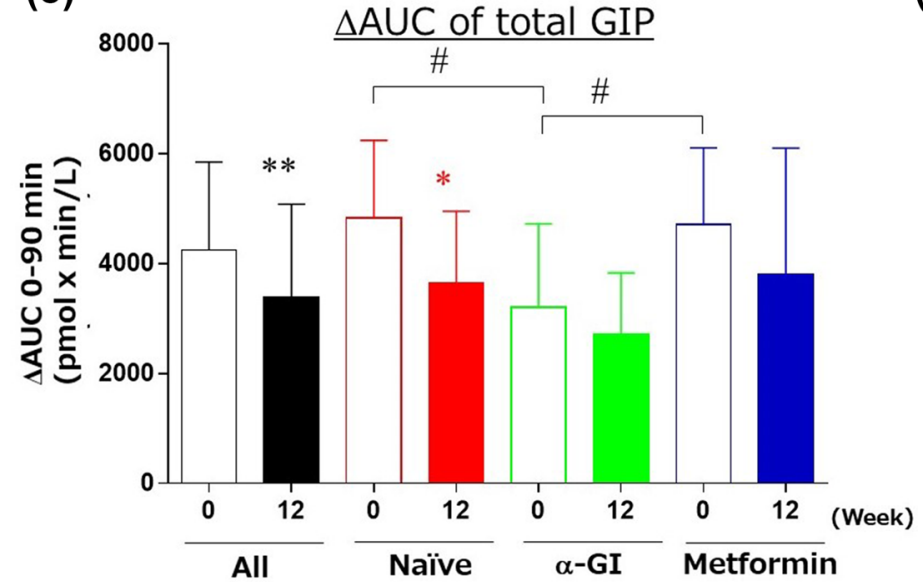

(b)

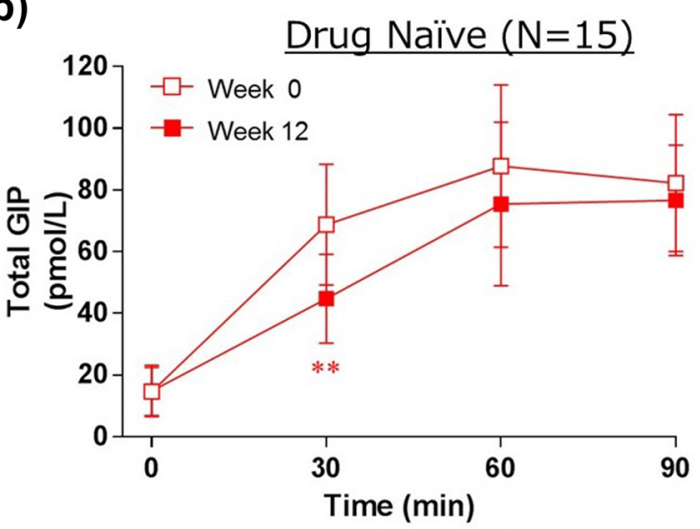

(d)

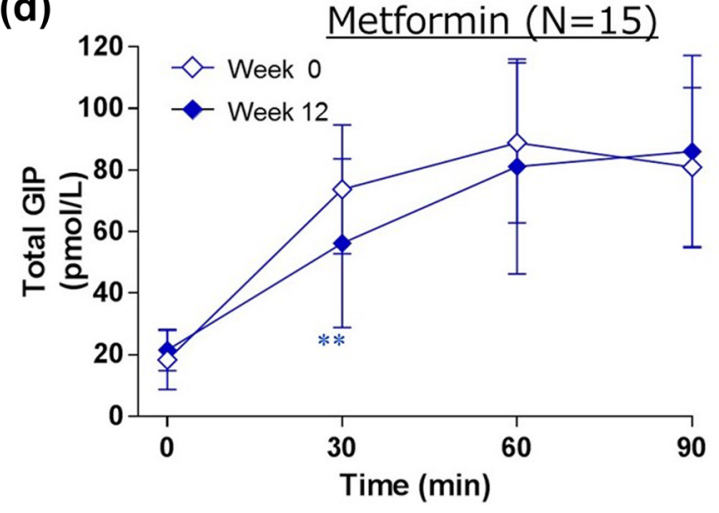

(f)

\section{$\%$ change in $\triangle A U C$ of total GIP}

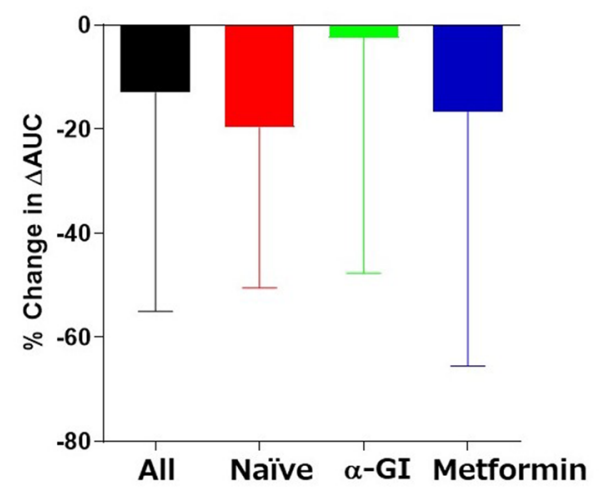

Fig. 3 Effect of canagliflozin on the postprandial plasma total GIP level in all patients (a), the drug-naïve group (b), the $\alpha$-GI group $(\mathbf{c})$, and the metformin group $(\mathbf{d})$, and on an incremental area under the curve ( $\triangle \mathrm{AUC}$ ) from 0 to $90 \mathrm{~min}(\mathbf{e})$, and the percentage change in $\triangle \mathrm{AUC}(\mathbf{f})$. Data are presented as the mean $\pm \mathrm{SD} .{ }^{*} P<0.05$ and ${ }^{* *} P<0.01$ in comparison with baseline (week 0 ) at each time point and that between pre- and post-treatment of canagliflozin in $\triangle$ AUC. ${ }^{\#} P<0.05$ for the comparison of $\triangle \mathrm{AUC}$ at baseline between the $\alpha$-GI group and the other two groups. No statistical differences were noted between the three groups in the percentage change in $\triangle \mathrm{AUC}$. GIP glucose-dependent insulinotropic polypeptide, GI glucosidase inhibitor, SD standard deviation 
(a)

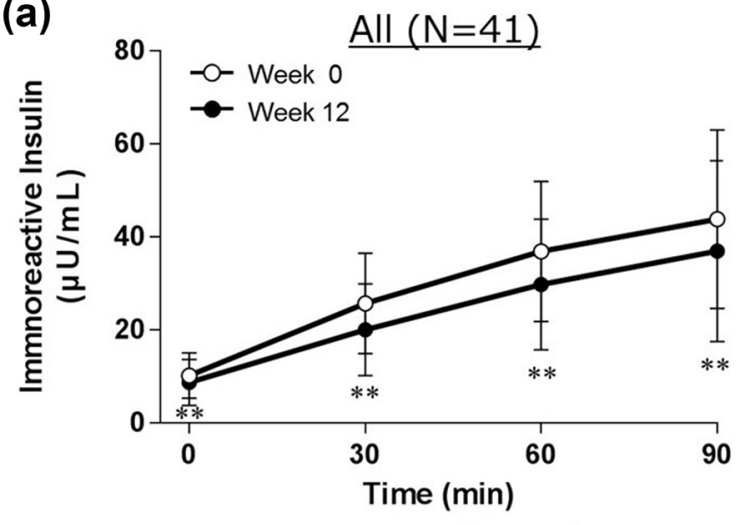

(c)

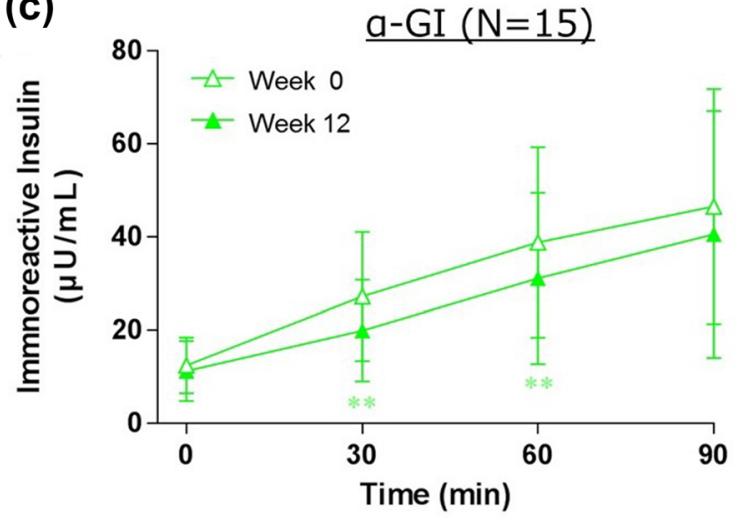

(e)

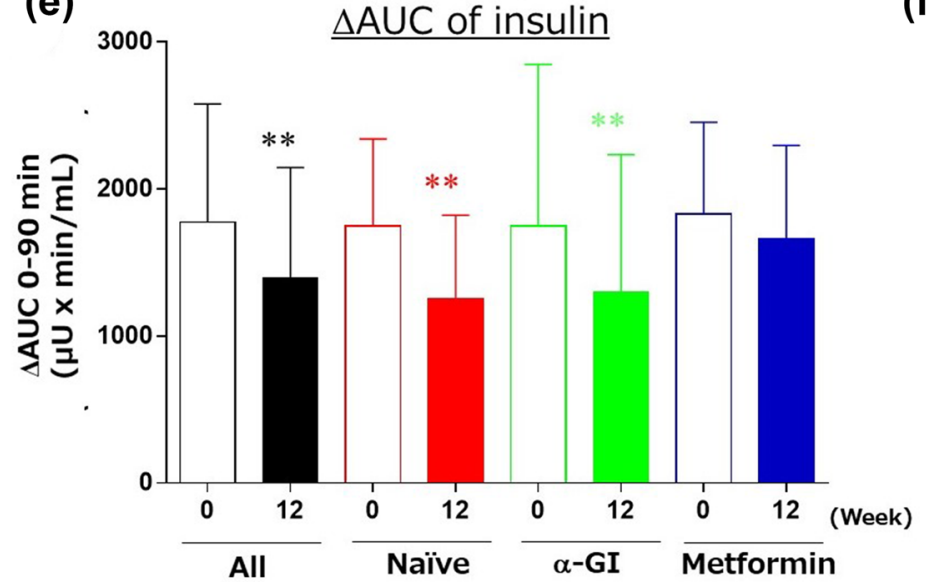

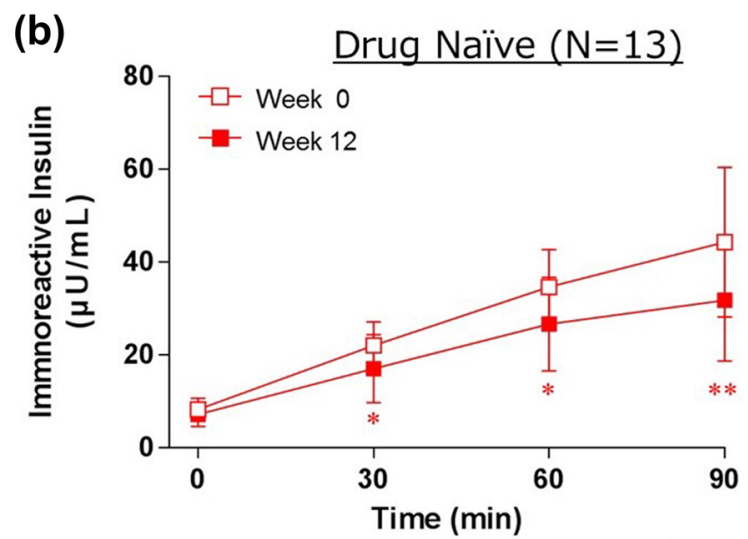

(d)

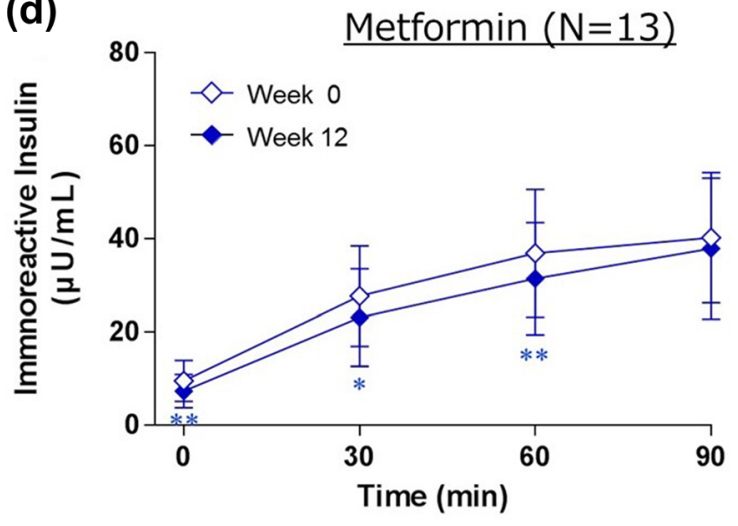

(f)
Fig. 4 Effect of canagliflozin on the postprandial serum immunoreactive insulin level in all patients (a), the drugnaive group (b), the $\alpha$-GI group (c), and the metformin group (d), and on an incremental area under the curve ( $\triangle \mathrm{AUC}$ ) from 0 to $90 \mathrm{~min}(\mathbf{e})$, and the percentage change in $\triangle$ AUC $(\mathbf{f})$. Data are presented as the mean $\pm S D$. ${ }^{*} P<0.05$ and ${ }^{* *} P<0.01$ in comparison with baseline (week 0) at each time point and that between pre- and post-treatment of canagliflozin in $\triangle A U C$. No statistical differences were noted between the three groups in $\triangle \mathrm{AUC}$ at baseline and the percentage change in $\triangle$ AUC. GIP glucose-dependent insulinotropic polypeptide, GI glucosidase inhibitor, SD standard deviation 
(a)

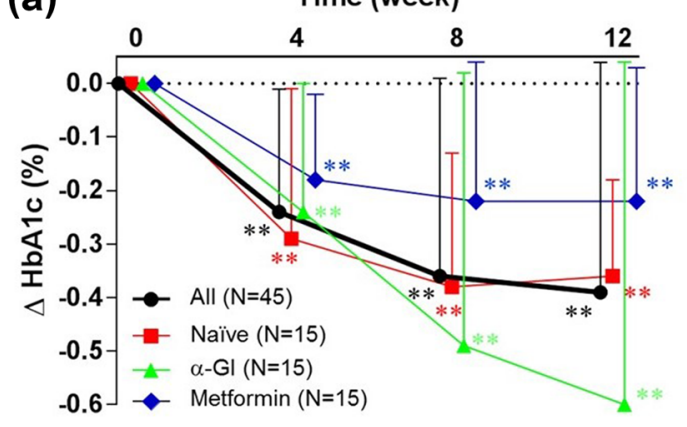

(c)

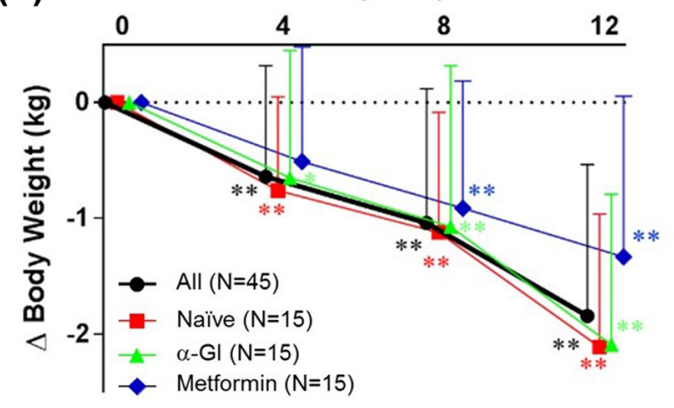

(e)

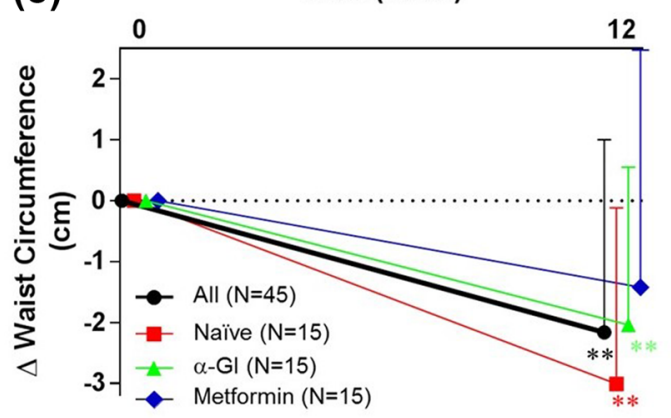

(b)

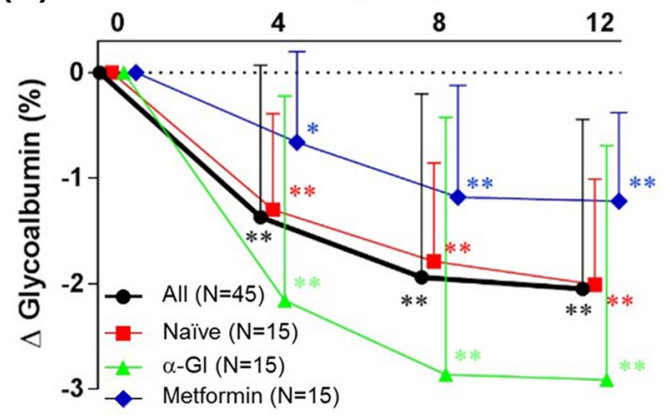

(d)

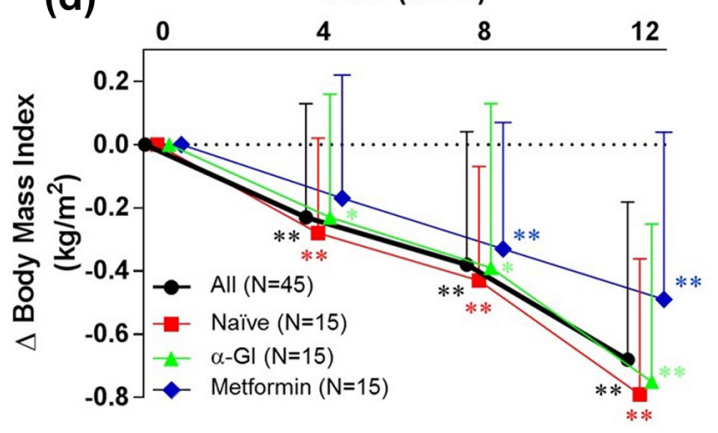

(f) Time (week)

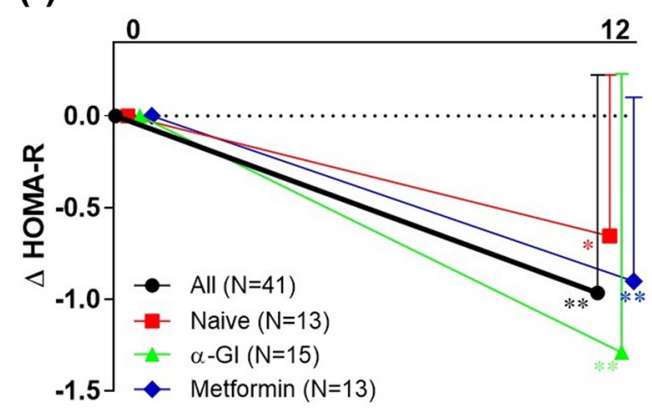

(g)

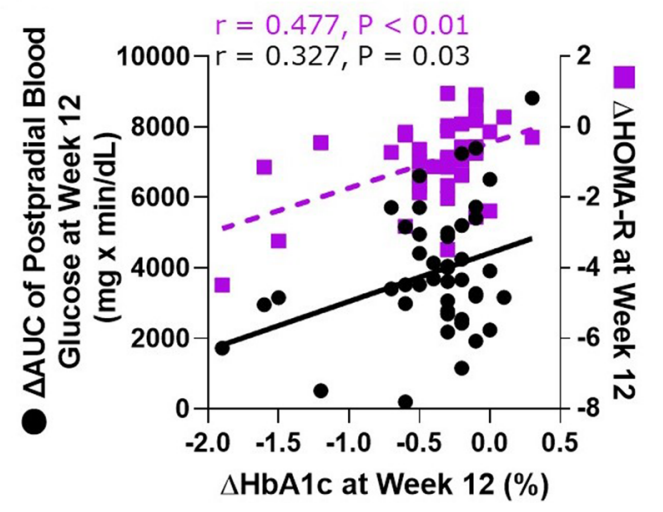


4 Fig. 5 Changes in HbAlc (a), glycoalbumin (b), body weight $(\mathbf{c})$, body mass index (d), waist circumference (e), and HOMA-R (f) during the treatment with canagliflozin, and relationship between the change in $\mathrm{HbAlc}$ and $\triangle \mathrm{AUC}$ of postprandial blood glucose or the change in HOMA-R at week $12(\mathbf{g})$. Data are presented as the mean $\pm S D .{ }^{*} P<0.05$ and ${ }^{* *} P<0.01$ in comparison with baseline (week 0). SD standard deviation, GI glucosidase inhibitor, $r$ correlation coefficient

and $60 \mathrm{~min}$ in the $\alpha$-GI group, and 0,30 , and $60 \mathrm{~min}$ in the metformin group $(P<0.05$ or $P<0.01)$. $\triangle$ AUC significantly decreased in all patients, the drug-naïve group, and the $\alpha$-GI group $(P<0.01)$, but not in the metformin group. The percentage change in $\triangle A U C$ of immunoreactive insulin levels from baseline was not significantly different between the groups (Fig. 4f).

To examine the relationship between blood glucose, total GLP-1, total GIP, and immunoreactive insulin levels, correlation analysis was performed. There was no correlation between each parameter value of the percentage change in $\triangle$ AUC (Fig. 1 in the supplementary material).

\section{Clinical Parameters}

HbA1c $(P<0.05)$ and glycoalbumin $(P<0.01)$ decreased significantly 4 weeks after the start of canagliflozin treatment and remained low up to 12 weeks in all patients and in each group. The changes in HbA1c (Fig. 5a) and glycoalbumin (Fig. 5b) levels from the baseline after treatment with canagliflozin for 12 weeks were greater in the $\alpha$-GI group than in the other groups. Body weight (Fig. 5c) and BMI (Fig. 5d) showed a gradual reduction in all patients and in each group from week 4 to week 12 after treatment with canagliflozin. The waist circumference showed a significant reduction after treatment with canagliflozin in all patients, the drug-naïve and $\alpha$-GI groups $(P<0.01)$, but not in the metformin group (Fig. 5e). HOMA-R showed a significant reduction after treatment with canagliflozin in all patients and in each group (Fig. 5f), but HOMA-B was not significantly changed after treatment with canagliflozin for
12 weeks in all patients (mean difference \pm SD $4.6 \pm 22.7$ ) and in each group.

To examine the relationship between the change in HbA1c and $\triangle A U C$ of postprandial blood glucose or the change in HOMA-R at week 12 , correlation analysis was performed. There was significantly correlation between each parameter value of the change in HbA1c and $\triangle$ AUC of postprandial blood glucose $(P<0.05)$ or the change in HOMA-R $(P<0.01)$ (Fig. 5g).

\section{Safety}

Canagliflozin $100 \mathrm{mg}$ once daily for 12 weeks was well tolerated in Japanese patients with T2DM, and none of the patients discontinued because of adverse events (AEs). Symptoms suggestive of glucose malabsorption and gastrointestinal AEs were not reported during the study period.

\section{DISCUSSION}

We found that canagliflozin $100 \mathrm{mg}$ significantly increased postprandial total GLP-1 levels and transiently decreased postprandial total GIP levels in the absence of acarbose in Japanese patients with T2DM. Our findings concur with data from clinical studies with healthy subjects, where canagliflozin $300 \mathrm{mg}$ decreased plasma GIP and increased plasma GLP-1 levels [9] and reduced postprandial blood glucose excursion due to delayed intestinal glucose absorption $[9,10]$.

Canagliflozin in combination with $\alpha$-GI did not alter total GLP-1 or GIP levels, despite a significant reduction in postprandial blood glucose levels. This may be attributed to canagliflozin's lower SGLT2 selectivity over SGLT1 compared with other SGLT2 inhibitors [3], and possibly its effect on intestinal SGLT1 inhibition after oral administration. This finding was further supported by simulation studies with a physiologically based pharmacokinetic and pharmacodynamic model, in which both canagliflozin $100 \mathrm{mg}$ and dapagliflozin $10 \mathrm{mg}$ completely inhibited SGLT2, but not SGLT1 in the renal proximal tubule. Inhibition of SGLT1 by 
dapagliflozin was less effective in the proximal intestine, whereas canagliflozin achieved 40-50\% inhibition in the duodenum and jejunum within 30 min after oral administration [25]. Since intestinal SGLT1 is pivotal for the intestinal mass absorption of glucose and triggers the glucose-dependent secretion of GIP and GLP-1 [4], the inhibition of SGLT1 in the small intestine and the inhibition of SGLT2 in the renal tubules mediate canagliflozin's transient inhibition of glucose absorption.

The $\alpha$-GIs delay the absorption of digested carbohydrates from the small intestine and also sustain the inhibition of the digestion of complex carbohydrates in the colon [14-16]. Furthermore, $\alpha$-GIs decrease the secretion of GIP and increase the secretion of GLP-1 in the intestine $[15,16]$. Indeed, our results showed that acarbose treatment significantly decreased postprandial total GIP levels and tended to increase postprandial total GLP-1 levels compared to the drug-naïve or metformin treatment before the start of canagliflozin treatment. It may be postulated that canagliflozin, after having exerted sufficient effect on $\alpha$-GI, showed insufficient synergism with acarbose. On the other hand, canagliflozin added on to acarbose significantly reduced postprandial blood glucose levels. This may be attributed to the dual blocking of glucose absorption in the upper intestinal tract via SGLT1 inhibition by canagliflozin and inhibition of a portion of glucose by $\alpha$-GI. Thus, we consider that the dual blocking of glucose absorption has no impact on the incretin response to the subsequent meal.

In contrast, the mechanism of canagliflozinmediated increase in GLP-1 differs from the GLP-1 secretion mechanism by metformin. This was evident from the significant increase in GLP-1 at all time points during the MTT $(P<0.01)$, for canagliflozin added on to metformin. In patients with T2DM, metformin reportedly induces GLP-1 secretion [17-19] indirectly through an increase in bile acids in the intestine [18] or directly by an AMP-activated protein kinase (AMPK)-dependent effect [19], without delayed intestinal glucose absorption.
Postprandial glucose control [26] and intensive glycemic control reduce the risk of diabetic complications $[27,28]$; the prevention of postprandial total glucose and incremental glycemic excursion decreases the risk for T2DM [29]. Reductions in HbA1c and glycoalbumin in the $\alpha$-GI group were greater than those in the other groups. Although the $\alpha$-GI group had improved postprandial glucose control before canagliflozin administration, its baseline HOMA-R, an index of insulin resistance, was high. In addition, the change in HbA1c level at week 12 was associated with not only the change in HOMA$\mathrm{R}$ but also in part $\triangle \mathrm{AUC}$ of postprandial blood glucose. These results suggest that canagliflozin may lead to the reduction in HbA1c levels mainly via improvement of insulin resistance by renal SGLT2 inhibition but, at least in part, via lowered postprandial glucose elevations through delayed glucose absorption in the intestine. Several studies have shown that SGLT2 inhibitors improve insulin resistance and secretion in patients with T2DM [30, 31]. In this study, no change in HOMA-B levels compared with baseline were noted in any of the canagliflozin-treated groups, because baseline HOMA-B was at a normal level.

Since the postprandial GLP-1 plays a major role in the control of glucose homeostasis [32], the extent of increased postprandial GLP-1 level on the reduction in blood glucose levels was investigated. Although we tried to analyze that the relationship between the percentage change in $\triangle$ AUC and the postprandial parameters, we could not find a correlation. A recent report showed that endogenous GIP affects postprandial plasma glucose excursions and insulin secretion more than endogenous GLP-1 in healthy individuals [33]. Therefore, a further precise study is necessary to evaluate to what extent an increased GLP-1 level contributes to a decrease in blood glucose level.

Some limitations of the present study warrant mention. First, an increased postprandial GLP-1 level by canagliflozin was associated with breakfast only and not tried with other meals. A recent report showed that canagliflozin was detected at high tissue concentration in the small intestine $24 \mathrm{~h}$ after administration in rats, and other SGLT2 inhibitors were not detected 
[34]. Second, the effect of concomitant therapy with dipeptidyl peptidase 4 (DPP-4) inhibitors, which inhibit GLP-1 degradation and prolong its effects, was not investigated, although canagliflozin has been reported to increase the plasma level of active GLP-1 in combination with DPP-4 inhibitors [35]. Third, comparative studies with other SGLT2 inhibitors are lacking. Sotagliflozin (LX4211), a dual SGLT1/SGLT2 inhibitor, reduced postprandial hyperglycemia and GIP, and increased GLP-1 levels in patents with T2DM, and these effects are thought to be induced through a transient SGLT1 inhibition in the upper intestine [36, 37]. Our study results were similar to those reported for LX4211. Whereas, empagliflozin, which has the highest SGLT2 selectivity, increased the GLP-1 level with a single, not 4-week, administration during $3 \mathrm{~h}$ of fasting and $5 \mathrm{~h}$ after mixed meal ingestion [38], probably via a mechanism distinct from that of canagliflozin. Therefore, the aforementioned durable, additive, or synergistic effects of canagliflozin alone and in combination with DPP-4 inhibitors, and comparison with other SGLT2 inhibitor-mediated incretin secretion may be future topics of discussion in the clinical setting.

\section{CONCLUSION}

Canagliflozin $100 \mathrm{mg}$ has an increased postprandial GLP-1 level in the absence of acarbose, suggesting that it may upregulate GLP-1 secretion through delayed glucose absorption in the intestine. Therefore, canagliflozin with dual actions of $\alpha$-GI-like effects and renal mechanism is expected to provide a beneficial effect in the treatment of patients with T2DM.

\section{ACKNOWLEDGEMENTS}

We thank the participants and the study personnel who participated in this study.

Funding. This study along with the Rapid Service Fee was funded by Mitsubishi Tanabe Pharma Corporation.
Authorship. All named authors meet the International Committee of Medical Journal Editors (ICMJE) criteria for authorship for this article, take responsibility for the integrity of the work as a whole, and have given their approval for this version to be published. All authors had full access to all of the data in this study and take complete responsibility for the integrity of the data and accuracy of the data analysis.

Disclosures. Takeshi Osonoi has received personal fees from Abbott, AbbVie GK, Astellas Pharma, AstraZeneca, Bayer Yakuhin, BristolMyers Squibb, Daiichi Sankyo, Eli Lilly, Japan Tobacco, Kowa Pharmaceutical, Kyowa Hakko Kirin, Mitsubishi Tanabe Pharma, MSD, Novo Nordisk Pharma, Novartis Pharma, Ono Pharmaceutical, Poxel SA, Sanofi, Sanwa Kagaku Kenkyusho, Sumitomo Dainippon Pharma, Takeda Pharmaceutical, and Terumo. Atsuko Tamasawa, Yusuke Osonoi, Kensuke Ofuchi, Makoto Katoh, and Miyoko Saito have nothing to disclose.

Compliance with Ethics Guidelines. The study protocol was approved by the Naka Kinen Clinic Institutional Review Board, Ibaraki, Japan, and is registered in the University Hospital Medical Information Network Clinical Trials Registry as UMIN000018345. All procedures performed in this study involving human participants were in accordance with the ethical standards of the responsible committee on human experimentation (institutional and national) and the Helsinki Declaration of 1964, as revised in 2013. Informed consent was obtained from all individual participants included in the study. Participants were compensated for their time.

Data Availability. The datasets generated during and/or analyzed during the current study are available from the corresponding author on reasonable request.

Open Access. This article is distributed under the terms of the Creative Commons Attribution-NonCommercial 4.0 International License (http://creativecommons.org/licenses/ 
by-nc/4.0/), which permits any noncommercial use, distribution, and reproduction in any medium, provided you give appropriate credit to the original author(s) and the source, provide a link to the Creative Commons license, and indicate if changes were made.

\section{REFERENCES}

1. Vallon V. The mechanisms and therapeutic potential of SGLT2 inhibitors in diabetes mellitus. Annu Rev Med. 2015;66:255-70.

2. DeFronzo RA, Norton L, Abdul-Ghani M. Renal, metabolic and cardiovascular considerations of SGLT2 inhibition. Nat Rev Nephrol. 2017;13:11-26.

3. Kurosaki E, Ogasawara H. Ipragliflozin and other sodium-glucose cotransporter-2 (SGLT2) inhibitors in the treatment of type 2 diabetes: preclinical and clinical data. Pharmacol Ther. 2013;139:51-9.

4. Gorboulev V, Schürmann A, Vallon $\mathrm{V}$, et al. $\mathrm{Na}(+)-$ D-glucose cotransporter SGLT1 is pivotal for intestinal glucose absorption and glucose-dependent incretin secretion. Diabetes. 2012;61:187-96.

5. Martín MG, Turk E, Lostao MP, Kerner C, Wright EM. Defects in Na+/glucose cotransporter (SGLT1) trafficking and function cause glucose-galactose malabsorption. Nat Genet. 1996;12:216-20.

6. Wright EM, Loo DDF, Hirayama BA. Biology of human sodium glucose transporters. Physiol Rev. 2011;91:733-94.

7. Chen J, Williams S, Ho S, et al. Quantitative PCR tissue expression profiling of the human SGLT2 gene and rectal family members. Diabetes Ther. 2010;1:57-92.

8. Oguma T, Nakayama K, Kuriyama C, et al. Intestinal sodium glucose cotransporter 1 inhibition enhances glucagon-like peptide-1 secretion in normal and diabetic rodents. J Pharmacol Exp Ther. 2015;354:279-89.

9. Polidori D, Sha S, Mudaliar S, et al. Canagliflozin lowers postprandial glucose and insulin by delaying intestinal glucose absorption in addition to increasing urinary glucose excretion. Diabetes Care. 2013;36:2154-61.

10. Sha S, Polidori D, Farrell K, et al. Pharmacodynamic differences between canagliflozin and dapagliflozin: results of a randomized, double-blind, crossover study. Diabetes Obes Metab. 2015;17:188-97.
11. Kim W, Egan JM. The role of incretins in glucose homeostasis and diabetes treatment. Pharmacol Rev. 2008;60:470-512.

12. Drucker DJ. The role of gut hormones in glucose homeostasis. J Clin Invest. 2007;117:24-32.

13. Holst JJ, Vilsbøll T, Deacon CF. The incretin system and its role in type 2 diabetes mellitus. Mol Cell Endocrinol. 2009;297:127-36.

14. Shibao C, Gamboa A, Diedrich A, et al. Acarbose, an $\alpha$-glucosidase inhibitor, attenuates postprandial hypotension in autonomic failure. Hypertension. 2007;50:54-61.

15. Lee A, Patrick P, Wishart J, Horowitz M, Morley JE. The effects of miglitol on glucagon-like peptide-1 secretion and appetite sensations in obese type 2 diabetics. Diabetes Obes Metab. 2002;4:329-35.

16. Aoki K, Miyazaki T, Nagakura J, Orime K, Togashi Y, Terauchi Y. Effects of pre-meal versus post-meal administration of miglitol on plasma glucagon-like peptide-1 and glucose-dependent insulinotropic polypeptide levels in healthy men. Endocr J. 2010;57:673-7.

17. Mulherin AJ, Oh AH, Kim H, Grieco A, Lauffer LM, Brubaker PL. Mechanisms underlying metformininduced secretion of glucagon-like peptide-1 from the intestinal $\mathrm{L}$ cell. Endocrinology. 2011;152:4610-9.

18. Scarpello JH, Hodgson E, Howlett HC. Effect of metformin on bile salt circulation and intestinal motility in type 2 diabetes mellitus. Diabet Med. 1998;15:651-6.

19. Bahne E, Sun EWL, Young RL, et al. Metformininduced glucagon-like peptide-1 secretion contributes to the actions of metformin in type 2 diabetes. JCI Insight. 2018;3(23):93936. https://doi. org/10.1172/jci.insight.93936.

20. Wu T, Bound MJ, Standfield SD, et al. Effects of rectal administration of taurocholic acid on glucagon-like peptide- 1 and peptide YY secretion in healthy humans. Diabetes Obes Metab. 2013;15:474-7.

21. Hansen M, Scheltema MJ, Sonne DP, et al. Effect of chenodeoxycholic acid and the bile acid sequestrant colesevelam on glucagon-like peptide-1 secretion. Diabetes Obes Metab. 2016;18:571-80.

22. Marina AL, Utzschneider KM, Wright LA, Montgomery BK, Marcovina SM, Kahn SE. Colesevelam improves oral but not intravenous glucose tolerance by a mechanism independent of insulin sensitivity and $\beta$-cell function. Diabetes Care. 2012;35:1119-25. 
23. Yabe D, Watanabe K, Sugawara K, et al. Comparison of incretin immunoassays with or without plasma extraction: incretin secretion in Japanese patients with type 2 diabetes. J Diabetes Invest. 2012;3:70-9.

24. Matthews DR, Hosker JP, Rudenski AS, et al. Homeostasis model assessment: insulin resistance and beta-cell function from fasting plasma glucose and insulin concentrations in man. Diabetologia. 1985;28:412-9.

25. Mori K, Saito R, Nakamaru Y, Shimizu M, Yamazaki H. Physiologically based pharmacokinetic-pharmacodynamic modeling to predict concentrations and actions of sodium-dependent glucose transporter 2 inhibitor canagliflozin in human intestines and renal tubules. Biopharm Drug Dispos. 2016;37:491-506.

26. Nakagami T, The DECODA Study Group. Hyperglycaemia and mortality from all causes and from cardiovascular disease in five populations of Asian origin. Diabetologia. 2004;47:385-94.

27. Dluhy RG, McMahon GT. Intensive glycemic control in the ACCORD and ADVANCE trials. N Engl J Med. 2008;358:2630-3.

28. Control Group, Turnbull FM, Abraira C, et al. Intensive glucose control and macrovascular outcomes in type 2 diabetes. Diabetologia. 2009;52:2288-98.

29. Standl E, Schnell O, Ceriello A. Postprandial hyperglycemia and glycemic variability. Diabetes Care. 2011;34:S120-7.

30. Ferrannini E, Muscelli E, Frascerra S, et al. Metabolic response to sodium-glucose cotransporter 2 inhibition in type 2 diabetic patients. J Clin Investig. 2014;124:499-508.

31. Kutoh E, Wada A, Murayama T, Hayashi J. Characterization of metabolic parameters in responders and nonresponders treated with canagliflozin monotherapy in drug-naive subjects with type 2 diabetes. Indian J Endocrinol Metab. 2018;22:185-90.

32. Heppner KM, Perez-Tilve D. GLP-1 based therapeutics: simultaneously combating T2DM and obesity. Front Neurosci. 2015;9:92. https://doi.org/ 10.3389/fnins.2015.00092 (eCollection 2015).

33. Gasbjerg LS, Helsted MM, Hartmann B, et al. Separate and combined glucometabolic effects of endogenous glucose-dependent insulinotropic polypeptide and glucagon-like peptide 1 in healthy individuals. Diabetes. 2019;68:906-17.

34. Sakaeda T, Kobuchi S, Yoshioka R, et al. Susceptibility to serious skin and subcutaneous tissue disorders and skin tissue distribution of sodiumdependent glucose co-transporter type 2 (SGLT2) inhibitors. Int J Med Sci. 2018;15:937-43.

35. Takebayashi K, Hara K, Terasawa T, et al. Effect of canagliflozin on circulating active GLP-1 levels in patients with type 2 diabetes: a randomized trial. Endocr J. 2017;64:923-31.

36. Zambrowicz B, Freiman J, Brown PM, et al. LX4211, a dual SGLT1/SGLT2 inhibitor, improved glycemic control in patients with type 2 diabetes in randomized, placebo-controlled trial. Clin Pharmacol Ther. 2012;92:158-69.

37. Powell DR, Smith M, Greer J, et al. LX4211 increases serum glucagon-like peptide 1 and peptide YY levels by reducing sodium/glucose cotransporter 1 (SGLT1)-mediated absorption of intestinal glucose. J Pharmacol Exp Ther. 2013;345:250-9.

38. Ferrannini E, Muscelli E, Frascerra S, et al. Metabolic response to sodium-glucose cotransporter 2 inhibition in type 2 diabetic patients. J Clin Investig. 2014;124:499-508. 